\title{
Mediação na atividade pedagógica: a unidade entre teoria e prática
}

Janaina Damasco Umbelino*

* (Universidade Estadual do Oeste do Paraná - Unioeste, campus de Francisco Beltrão, Paraná, Brasil).
Resumo: Este artigo apresenta os resultados de uma pesquisa realizada no Brasil e em Cuba que tem como objetivo compreender os elementos mediadores da atividade pedagógica para uma educação de melhor qualidade que promova o desenvolvimento das máximas potencialidades da criança. Inicialmente apresentamos nossa compreensão de desenvolvimento humano, resultado das relações sociais, e abordamos os elementos dessas relações, particularmente os vinculados à atividade pedagógica, entendida como a unidade entre a atividade de ensino e a atividade de estudo. Por fim, destacamos que para a organização da atividade pedagógica, promotora do desenvolvimento humano, é necessário compreender os elementos que constituem o desenvolvimento da criança, voltados a uma educação que proporcione situações de aprendizagem adequadas ao nível de desenvolvimento da criança e à sua situação social de desenvolvimento.

Palavras-chave: Teoria Histórico-cultural. Desenvolvimento humano. Atividade pedagógica. 


\section{INTRODUÇÃO}

A organização do ensino e a apropriação do conhecimento pelas crianças de escolas públicas brasileiras é motivo de grande discussão, principalmente no que se refere ao sucesso e fracasso escolar. Percebemos que as crianças avançam, nos anos da Educação Básica, com dificuldades na apropriação da leitura e escrita nas diferentes áreas de conhecimento. A organização do sistema de ensino está voltada para responder às exigências dos sistemas de avaliação e não à formação de seres humanos conscientes de que são sujeitos da história. 0 resultado disso são baixos níveis de alfabetização na língua portuguesa e em matemática.

Subsumidos às precárias condições de trabalho docente, os professores se "queixam" do comportamento das crianças, enfatizando o desinteresse delas pela aprendizagem. Culpabilizam-nas por não aprenderem ou não atingirem o mesmo desempenho escolar de um aluno ideal. Também, a condição social das crianças de escolas públicas não permite que supram, em vários casos, nem mesmo suas necessidades biológicas. Isso demanda à escola ações mais assistencialistas do que aquelas necessárias para a formação humana e, em particular, a apropriação da cultura.

Na tentativa de reverter essa situação, no âmbito de políticas públicas de educação, programas governamentais são implantados com os objetivos de reduzir os índices de analfabetismo, garantir a permanência na escola e incentivar a formação de professores. Como exemplos, podemos citar:

- Brasil Alfabetizado ${ }^{1}$, que desde 2003 atende municípios, principalmente na Região Nordeste, com o objetivo de alfabetizar jovens e adultos a partir dos 15 anos. O principal objetivo do programa é apoiar a educação de jovens, adultos e idosos, garantindo como política pública melhorar a oferta da educação para esse público.

- Pacto Nacional pela Alfabetização na Idade Certa (Pnaic)², implantado em 2012. Tem o objetivo de assegurar que as crianças estejam alfabetizadas até os 8 anos de idade. Dá apoio, por meio de formação continuada e bolsa de auxílio financeiro, aos professores que atuam nesse período da Educação Básica. A partir de 2018, o Pnaic inseriu na formação professores da Educação Infantil,

Mais informações em: 〈http://portal.mec.gov.br/programa-brasil-alfabetizado〉.

Mais informações em: 〈http://www.fnde.gov.br/programas/bolsas-e-auxilios/ eixos-de-atuacao/lista-de-programas/item/6433-pacto-nacional-pelaalfabetiza\%C3\%A7\%C3\%A3o-da-idade-certa-\%E2\%80\%93-pnaic>. 
como meio de garantir às crianças a alfabetização até o final do 1ํ Ciclo.

- Programa Mais Alfabetização³, implantado em fevereiro de 2018, tem 0 objetivo de fortalecer e apoiar o processo de alfabetização (leitura, escrita e matemática) das crianças de $1^{\circ}$ e $2^{\circ}$ anos do Ensino Fundamental. 0 programa consiste na contratação de um "assistente de alfabetização" para o professor, por 5 ou 10 horas semanais, respectivamente, para escolas não vulneráveis e vulneráveis (de acordo com a Portaria n. 142, de 22 de fevereiro de 2018).

- Programa Mais Educação ${ }^{4}$ implantado a partir de 2018, está organizado para melhorar as condições de permanência e alfabetização na língua portuguesa e em matemática do $4^{\circ}, 5^{\circ}$, $8^{\circ}$ e e $9^{\circ}$ anos do Ensino Fundamental. 0 projeto é realizado por meio da participação dos estudantes em diferentes atividades nas diversas áreas do conhecimento. Atuam no programa: profissionais da educação, professores voluntários, educadores populares, monitores e estudantes universitários em formação nas diferentes áreas que compõem o programa.

- Rede Nacional de Formação Continuada de Professores ${ }^{5}$, criada em 2004, organizada para a melhoria e incentivo à formação de professores. Fazem parte da Rede instituições públicas de Ensino Superior, que produzem materiais para a formação a distância e semipresenciais de professores da Educação Básica. As áreas de formação são: alfabetização e linguagem, educação matemática e científica, ensino de ciências humanas e sociais, artes e educação física.

Entretanto, mesmo com a criação e implantação desses programas, ainda observamos que os índices de apropriação da leitura e da linguagem escrita não aumentam, mantendo níveis básicos de alfabetização.

Vários documentos, como propostas curriculares dos estados e municípios, apresentam uma compreensão de educação promotora do desenvolvimento humano que garanta a todas as crianças o direito à educação e o acesso ao conhecimento. Porém, a realidade encontrada demonstra a distância entre o que é proposto nesses documentos e as condições objetivas para a realização de um trabalho que efetive o desenvolvimento humano omnilateral ${ }^{6}$ na criança.

3 Mais informações em: 〈http://portal.mec.gov.br/programa-nacional-biblioteca-daescola/30000-uncategorised/62871-programa-mais-alfabetizacao〉.

4 Mais informações em: 〈http://portal.mec.gov.br/dmdocuments/passoapasso_ maiseducacao.pdf $\rangle$.

Mais informações em: 〈http://portal.mec.gov.br/rede-nacional-de-formacao-continuadade-professores.

6 Compreendemos por desenvolvimento humano ominilateral o desenvolvimento do homem em sua totalidade. Ou seja, o desenvolvimento de suas funções físicas e psíquicas necessárias para o convívio em sociedade. 
Isso resulta em níveis rudimentares de alfabetização e uma escola que não garante a apropriação das habilidades de leitura e escrita. Desse modo, nos perguntamos: como organizar uma atividade pedagógica que promova o desenvolvimento humano omnilateral?

Partimos da compreensão de que o desenvolvimento humano ocorre mediado pelas relações sociais das quais a criança participa ativamente. Por meio dessas relações, mediadas pelos artefatos culturais da atuação do "outro" com o "outro", e de si mesma, num movimento de produção histórica de sua existência, a criança se apropria das características específicas humanas, ou seja, torna-se humana.

Dessa forma, é nas relações sociais que a mediação ocorre. 0 conceito de mediação se configura, então, como um dos conceitos centrais na teoria produzida por L. S. Vigotski. Segundo Leontiev, “permite estabelecer uma unidade universal nova e adequada para a estruturação das funções psíquicas" (1991, p. 438). Porém, o que significa o conceito de mediação? Que elementos mediadores constituem a atividade pedagógica, e as relações sociais, para a promoção do desenvolvimento humano? Qual é o papel do professor nesse processo?

Na tentativa de responder, apresentamos neste texto algumas considerações sobre os elementos mediadores na atividade pedagógica organizada para a promoção do desenvolvimento humano omnilateral. Compreendemos que eles explicitam a história do desenvolvimento do homem na produção humana de sua existência. Esses elementos, constituídos e constituintes da atividade pedagógica, por sua vez, também, integram o complexo das relações sociais. Promovem a formação da personalidade da criança ao dar movimento à lei geral do desenvolvimento humano, na qual as relações interpsíquicas se transformam em relações intrapsíquicas.

É importante salientar nosso entendimento sobre o desenvolvimento humano omnilateral. Compreendemos o desenvolvimento do homem em sua omnilateralidade, ou seja, em sua totalidade, visando uma educação voltada para o desenvolvimento integral do ser humano, "das faculdades e das forças produtivas, das necessidades e da capacidade da sua satisfação" (MANACORDA, 2007, p. 87). Isso significa que é permitido a ele desenvolver suas capacidades psíquicas para que produza e reproduza sua própria existência. Que aproprie o conhecimento produzido pela humanidade, ao longo da história, para que possa ter autonomia para realizar escolhas. 
Para isso, consideramos que a educação necessita promover uma atividade pedagógica voltada para o desenvolvimento do sistema de funções psíquicas superiores, visto que são essas funções que proporcionam a apropriação, pelo ser humano, dos conhecimentos teóricos, dos valores éticos e morais, do desenvolvimento de habilidades que garantem o agir humano de maneira consciente e intencional. Uma educação condizente com esses objetivos está preocupada com a formação da personalidade dos sujeitos para que sejam produtores de sua história.

Na tentativa de compreender como se organizaria uma educação formulada a partir do pressuposto do desenvolvimento humano omnilateral, buscamos dados empíricos para o nosso estudo. Encontramos, na experiência educacional cubana, elementos já reconhecidos internacionalmente de uma educação estruturada para promover o desenvolvimento das crianças em sua totalidade.

Com esse objetivo, realizamos um estágio doutoral com pesquisadores e educadores cubanos. Nossos dados foram coletados por meio de visitas e observações a instituições de educação pré-escolar e educação primária7, entrevistas e discussões teóricas sobre a história da educação cubana e como os pressupostos da Teoria Histórico-cultural estavam presentes ao longo de, aproximadamente, 50 anos. Alguns de nossos interlocutores foram professores que atuaram efetivamente na organização de uma educação revolucionária.

Como tínhamos em mãos dados empíricos suficientes para estudar esse objeto numa experiência histórica concreta, definimos como objetivo do nosso trabalho identificar os elementos mediadores na atividade pedagógica organizada para a promoção do desenvolvimento humano omnilateral na educação cubana.

A história de Cuba é conhecida por nós, e seu exemplo para a América Latina não pode ser negado. Após o Triunfo da Revolução, o país luta para manter um sistema político sob um bloqueio econômico de mais de 50 anos. Em sua história, muitas ações organizadas coletivamente demonstram a preocupação em promover uma sociedade que se contrapõe à "hegemonia do Capital”. Para tanto, os cubanos e cubanas, por meio de um árduo processo histórico, buscam organizar uma formação social dirigida à produção de uma educação e saúde da melhor qualidade, tornando-se referência, principalmente, na América Latina.

Em Cuba, a educação pré-escolar equivale à Educação Infantil no Brasil. Já a educação primária seria o Ensino Fundamental I ou anos iniciais do Ensino Fundamental. 
Cuba mantém, aproximadamente, $100 \%$ das crianças na escola, e quase o mesmo percentual de crianças alfabetizadas. E, segundo dados da Organização das Nações Unidas (ONU) ${ }^{8}$, é o oitavo país com elevado índice de desenvolvimento humano do continente latino-americano e do Caribe. Esses dados manifestam uma política social comprometida com a realização de uma educação da melhor qualidade para crianças e jovens. Na história política do país, vários fatores contribuíram para que fossem criadas as condições objetivas a fim de que tais resultados realmente se efetivassem.

Uma delas é a formulação e implantação de uma proposta de educação promotora do desenvolvimento integral da criança. Tal política social permitiu a realização de investigações por pesquisadores cubanos, voltadas a compreender o desenvolvimento humano na criança e, assim, garantir seu pleno desenvolvimento. Inicialmente, estas ocorreram a partir dos estudos do materialismo histórico e dialético, efetuados, no país, após o Triunfo da Revolução. Depois, os fundamentos da Teoria Histórico-cultural foram incorporados a essa proposta, por serem compatíveis com os objetivos propostos.

Essas pesquisas deram origem a um sistema educacional que visa a garantir à criança um conjunto de ações que promova o desenvolvimento do sistema das funções psíquicas superiores e a formação de sua personalidade. E que, ao mesmo tempo, assegure as bases necessárias para apropriar-se do legado cultural produzido historicamente e, assim, formar as qualidades humanas em cada ser.

Essa experiência permitiu formar valores basilares da sociedade cubana. Apesar das históricas dificuldades, a educação é oferecida gratuitamente de forma a atender a todos. Isso evidencia uma política efetiva de atendimento à criança que mantém o atendimento de mais de 90\% das crianças de 0 a 6 anos de vida, pelas vias formais e não formais, e um atendimento de $100 \%$ na educação primária e secundária.

\section{RELAÇÃo ENTRE OS PROCESSOS DE MEDIAÇÃO E do DESENVOLVIMENTO HUMANO}

Para os pesquisadores da área da Educação, preocupados em compreender o processo de aprendizagem a partir dos fundamentos da Teoria Históricocultural, é por meio das e pelas relações sociais que as crianças se apropriam

Dados do Relatório de Desenvolvimento Humano 2016.

9 Educação primária e educação secundária correspondem aos anos iniciais e finais do Ensino Fundamental do sistema de ensino brasileiro. 
do legado cultural produzido pelo homem na história de sua ontogênese. Esses pesquisadores compreendem que é necessário oportunizar às crianças o acesso à produção histórica para que se continue ampliando as relações entre o homem e a natureza.

Ao criar novos elementos culturais, os sujeitos produzem a si mesmos, criam novas formas de se relacionar, de viver entre si e novas características do desenvolvimento humano. Surge, assim, um novo homem de acordo com o momento histórico em que ele vive. Todo esse processo é resultado do trabalho humano, ou, como enfatizaremos neste artigo, da atividade humana.

No senso comum, o conceito de atividade é utilizado principalmente para definir o uso de ações para alcançar um objetivo; também pode estar relacionado à atuação profissional, ou, ainda, pode ser usado quando algo está em funcionamento. Segundo Sánchez Vázquez (2007), o conceito de atividade não se restringe a ações físicas específicas. Pode referir-se a operações mais amplas e complexas, que acontecem na natureza e no meio social, como reações químicas, como o uso de elementos da natureza por animais de forma instintiva e ações que têm como base a percepção sensório-motora.

Partimos do entendimento de que atividade humana é o conjunto integrado por ações conscientes, estabelecidas no conjunto das relações sociais, que promovem o movimento de formação e de desenvolvimento de funções psíquicas e resultam no desenvolvimento humano. Como apresentado por Marx, em $O$ capital (1988, p. 146), o trabalho é uma atividade especificamente humana, “orientada a um fim". Os resultados alcançados por meio do trabalho surgem na forma de instrumentos e elementos da cultura, determinados pelo contexto histórico em que são produzidos.

Dessa forma, o conceito de atividade pode ser compreendido como um conjunto de ações físicas e mentais que produzem na materialidade - objetos e ideias - o que é planejado na consciência do homem.

Como um ato específico humano, a atividade se torna mais complexa, sendo necessário identificar os elementos que a compõem. A atividade humana caracteriza-se pelo conjunto de funções psicológicas colocadas em movimento para a realização de algo. 0 homem, ao colocar-se em atividade, principalmente planeja, analisa, imagina, faz uso de instrumentos e signos para um objetivo determinado. Opera conjuntamente as funções psíquicas como a memória, a linguagem, a percepção, a sensação, entre outras. 
Na Teoria Histórico-cultural, o conceito de atividade é discutido por Vigotski a partir da compreensão de que, quando o sujeito está em atividade, suas funções psicológicas se desenvolvem. Assim, é na atividade realizada, de forma planejada e consciente, que se manifestam e são desenvolvidas as funções psíquicas superiores. Nesse sentido, Vigotski destaca a importância do "outro" no desenvolvimento dessas funções.

Árias Beatón (2005), a partir da Teoria Histórico-cultural, define os “outros” como: [...] os adultos e os coetâneos de maior desenvolvimento ou mais avançados. Inclui-se nos adultos: as professoras e os professores, as mães e os pais, ou seja, todas aquelas pessoas portadoras dos conteúdos da cultura, que permitem que os sujeitos em desenvolvimento se apropriem deles. Isto definiu Vygostki na metade de 1930, aproximadamente (ÁRIAS BEATÓN, 2005, p. 230-231, grifo nosso).

O autor destaca, ainda, que na definição desses “outros” também é necessário inserir o "grupo", os "meios técnicos interativos", pois esses se caracterizam como "potencializadores" do desenvolvimento. Inclui como "outro" o próprio sujeito, ou seja, ele é mediador de si mesmo, quando começam os processos de "autorregulação; autodesenvolvimento, autoconsciência, autovaloração; nosso eu mesmo, nosso eu, como consequência de todo o desenvolvimento e a formação anterior, impulsiona nosso próprio desenvolvimento" (ÁRIAS BEATÓN, 2005, p. 231).

Na Teoria Histórico-cultural, a mediação é considerada um importante elemento na constituição da consciência. Esse conceito está frequentemente presente nas teses e dissertações fundamentadas na teoria produzida por Vigotski. Porém, defini-lo não é uma tarefa fácil; seu estudo ultrapassa os limites disciplinares, e sua complexidade pode apresentar diferentes interpretações.

É comum identificarmos, em diferentes trabalhos sobre os estudos de Vigotski, a afirmação de que a atividade do homem é uma atividade mediada por signos e instrumentos, ou seja, elementos presentes na relação do sujeito com o objeto para a realização de uma atividade. Isso forma parte do processo mediado em sua totalidade.

A tese principal de Vigotski ${ }^{10}$ é que a consciência humana se forma por meio da mediação dos elementos que constituem a cultura. Davydov e Zinchenko (1995, p. 164), ao destacarem o estudo de Vigotski sobre o desenvolvimento da consciência, afirmam que

10 Davydov e Zinchenko (1995, p. 164), destacam que o interesse científico de Vigotski se concentrava no "desenvolvimento da consciência humana, o desenvolvimento da mente humana". 
para Vygotsky, a determinação da consciência individual segue este esquema: atividade social coletiva - cultura-signos-atividade individual - consciência individual. O estudo do desenvolvimento da consciência individual exige o exame da transformação de todos os aspectos desse esquema. ${ }^{11}$

O homem, diferente dos animais, consegue estabelecer distintas conexões entre esses elementos, produzindo uma síntese que resultará numa ação direcionada a um objeto ou a uma situação. Ao realizá-la, em seu processo de objetivação, essa ação influencia outros e também será mediada por outros. Dessa forma, ele produz e é produtor de significados.

Para Vygotski (1995, p. 95), a mediação pode se caracterizar pelo uso de instrumentos enquanto ferramentas que modificam a estrutura dos objetos. Nesse sentido,

a aplicação de meios auxiliares em direção à atividade mediadora reestrutura toda a operação psíquica, do mesmo modo que a aplicação de ferramentas modifica a atividade natural dos órgãos e amplia, infinitamente o sistema de atividade das funções psíquicas. Tanto um como o outro, o denominamos, em seu conjunto de função psíquica superior ou conduta superior.

Já o signo “não modifica nada o objeto da operação psicológica. Constitui um meio da atividade interna dirigido para o controle do próprio indivíduo; o signo é orientado internamente" (VYGOTSKI, 1995, p. 94, grifo nosso). A atividade interna e a externa são atividades diferentes, de naturezas diferentes, mas que se constituem em unidade.

O uso de instrumentos e de signos se constitui, inicialmente, no social. Os sujeitos se apropriam deles por meio das relações sociais, a partir da mediação do outro, e ao mesmo tempo os utilizam como elementos mediadores de sua própria ação. Dessa forma,

poderíamos dizer, de outro modo, que as funções superiores não são produto da biologia, nem da história da filogênese pura, mas que o próprio mecanismo que subjaz nas funções psíquicas superiores é uma cópia do social. Todas as funções psíquicas superiores são relações interiorizadas de ordem social, são o fundamento da estrutura social da personalidade. Sua composição, estrutura genética e modo de ação, em uma palavra, toda sua natureza é social; inclusive ao converter-se em processos psíquicos segue sendo quase social. O homem, inclusive sozinho consigo mesmo, conserva funções de comunicação (VYGOTSKI, 1995, p. 151).

${ }_{11}$ Para saber mais sobre a relação entre atividade social coletiva e atividade individual, sugerimos a leitura de E. V. Ilienkov (1977), Lógica dialectica: ensayos de historia y teoria. 
Pino (1991, p. 32, grifo nosso) afirma que a mediação semiótica nos ajuda a compreender "os processos de internalização e objetivação, as relações entre pensamento e linguagem ou a interação entre sujeito e objeto do conhecimento, questão fundamental da teoria do conhecimento". Essa afirmação demonstra a importância do papel da mediação na teoria. Sendo assim, precisamos compreender como instrumento e signo se unem no processo de desenvolvimento do humano.

Ao usar os instrumentos, o homem amplia a extensão de sua própria força, modifica sua própria natureza e torna as suas funções psicológicas mais complexas. 0 autor passa a identificá-las com o termo "função psicológica superior, ou comportamento superior com referência à combinação entre o instrumento e o signo na atividade psicológica" (VYGOTSKY, 1994, p. 73, grifos do autor).

A compreensão do uso de instrumentos na atividade do sujeito voltada a um objeto, no desenvolvimento da inteligência prática da criança, resulta em um rico estudo na obra de Vigotski. O autor, ao analisar a conduta do homem, compreende que o elemento colocado entre o sujeito e o objeto promove uma mudança qualitativa em sua ação.

Assim, a atividade mediadora exerce um papel central nas formas superiores de pensamento, apresentando um caráter histórico e social, por ser composta por elementos produzidos pelo próprio homem no conjunto das relações sociais de produção da sua existência.

A partir do que afirmamos anteriormente, compreendemos a atividade humana como toda a ação coletiva voltada a um fim. Ela é representada idealmente, ou seja, planejada mentalmente. Movimenta um conjunto de forças físicas e mentais para alcançar seu objetivo. Então, nos perguntamos: que relações podemos estabelecer entre atividade humana e educação? Entre ensino e desenvolvimento humano? Cabe definir a relação entre atividade e educação. São essas questões que norteiam a discussão a ser apresentada na próxima seção.

\section{Atividade humana e EducaÇÃo escolar}

A educação é um ato especificamente humano, no qual os indivíduos se humanizam, ou seja, se apropriam das características humanas que não são "dadas" a priori aos homens, mas que precisam ser desenvolvidas por meio do processo de aprendizagem. Esse ato de produzir o humano no humano dá-se por meio da atividade de educar, que, segundo José Martí (1997, p. 67), 
é depositar em cada homem toda a obra humana que lhe antecedeu: é fazer de cada homem resumo do mundo vivente, até o dia em que vive: é colocá-lo em nível de seu tempo, para que flutue sobre ele, e não deixá-lo abaixo de seu tempo, com o que não poderá sair a flutuar, é preparar o homem para a vida.

Apesar de se fundamentar em outras bases teóricas, diferentes daquelas apresentadas por Martí, Leontiev (2004) também nos apresenta a compreensão do que é a atividade da educação. Para o autor,

as aquisições do desenvolvimento histórico das aptidões humanas não são simplesmente dadas aos homens nos fenômenos objetivos da cultura material e espiritual que os encarnam, mas são aí apenas postas. Para se apropriar destes resultados, para fazer deles

as suas aptidões, “os órgãos da sua individualidade”, as crianças, o ser humano, deve entrar em relação com os fenômenos do mundo circundante através de outros homens, isto é, num processo de comunicação com eles. Assim, a criança aprende a atividade adequada. Pela sua função esse processo é, portanto, um processo de educação (LEONTIEV, 2004, p. 290, grifos do autor).

Podemos afirmar que o ato de educar dá origem à atividade pedagógica, que possui características específicas como atividade humana. 0 professor é 0 responsável por esse tipo de atividade, e é sua responsabilidade planejar e organizar os "conteúdos" que dizem respeito à educação, que podem ser definidos como o conjunto de conhecimentos produzidos pela humanidade, “ideias, conceitos, valores, símbolos, hábitos, atitudes, habilidades” (LEONTIEV, 2004, p. 209).

Segundo a Teoria Histórico-cultural, a educação tem a função de promover o desenvolvimento humano omnilateral a partir das atividades de ensino e de aprendizagem, que

se corretamente organizada, a educação permitirá à criança desenvolver-se intelectualmente e criará toda uma série de processos de desenvolvimento que seriam impossíveis sem a educação. A educação revela-se, portanto, um aspecto internamente necessário e universal do processo de desenvolvimento, na criança, das características

históricas do homem, e não de suas características naturais (VIGOTSKI, 1956 apud DAVYDOV; ZINCHENKO, 1995, p. 161)

É por meio da educação que a atividade pedagógica ocorre. A atividade pedagógica, entendida como a unidade entre a atividade de estudo do estudante e a atividade de ensino do professor, tem o objetivo de promover situações de ensino e de aprendizagem. Quando organizada para proporcionar o desenvolvimento de novas formações psíquicas no estudante, resulta em 
um desenvolvimento crescente, na escola, dos principais sujeitos envolvidos - professores e estudantes.

As relações entre aprendizagem e desenvolvimento formam uma unidade. No entanto, esses processos não se sobrepõem entre si. A apropriação do conhecimento e demais conteúdos da cultura promovem o desenvolvimento de habilidades humanas e funções psíquicas que potencialmente são desenvolvidas, porém não naturalmente, somente com a mediação do "outro" mais experiente, participante das relações sociais.

Moura (2010), ao explicar a atividade pedagógica como unidade formadora do ser humano, esclarece que

a atividade do ensino do professor deve gerar e promover a atividade do estudante. Ela deve criar nele um motivo especial para a sua atividade: estudar e aprender teoricamente sobre a realidade. É com essa intenção que o professor planeja sua própria atividade e suas ações de orientação, organização e avaliação. Entretanto, considerando que a formação do pensamento teórico e da conduta cultural só é possivel como resultado da própria atividade do homem, decorre que tão importante quanto a atividade de ensino do professor é a atividade de aprendizagem que o estudante desenvolve (MOURA, 2010, p. 90, grifos nossos).

O professor, ao pensar, planejar a atividade de ensino, proporciona situações promotoras da aprendizagem, especialmente do conhecimento teórico produzido pela humanidade, por parte do estudante, e, ao mesmo tempo, se apropria do conhecimento teórico específico da atividade de ensino. Nesse movimento, portanto, as relações entre aprendizagem e desenvolvimento humano se evidenciam.

Por isso, a "aprendizagem escolar orienta e estimula os processos internos do desenvolvimento" (VIGOTSKI, 2001, p. 116). A ação de planejar o conjunto de ações, por meio de mediações necessárias para que o estudante se aproprie do legado cultural produzido pela humanidade, é pressuposto para que se realize a atividade pedagógica. Esse conjunto de ações planejadas pelo professor faz parte da atividade de ensino, que tem como finalidade "promover a humanização dos indivíduos por meio da aprendizagem do conhecimento elaborado historicamente no contexto escolar" (BERNARDES, 2012, p. 79).

Esse ato de promover a humanização nos indivíduos acaba dando origem à realização de uma atividade particular dos estudantes, com característica e estrutura específicas, denominada por V. Davidov, fundamentado nos estudos realizados principalmente por Vigotski e Leontiev, de atividade de estudo. Esta, enquanto atividade humana, é a principal atividade na idade escolar e tem como característica determinar “[...] o surgimento das principais 
neoformações psicológicas da idade dada, define o desenvolvimento psíquico geral dos estudantes de menor idade, a formação de sua personalidade em conjunto" (DAVIDOV, 1988, p. 159).

É importante ressaltar que essa atividade só ocorre por meio das relações sociais de produção da existência dos estudantes, entre elas a relação com a atividade de ensino - "isso não significa que haja correspondência direta entre o ensino e o desenvolvimento do indivíduo, mas sim que o ensino é uma forma necessária e relevante para o desenvolvimento" (DAVIDOV, 1988, p. 91).

A atividade de estudo tem como conteúdo os conhecimentos teóricos, as atitudes e hábitos presentes nas inúmeras criações culturais a serem apropriadas. Sua realização coloca em operação, pelo sujeito que aprende, diferentes funções psicológicas em direção ao desenvolvimento teórico. Segundo Davidov (1988, p. 158),

nos processos de estudos, como atividade principal na idade escolar inicial, as crianças reproduzem não somente os conhecimentos e habilidades correspondentes aos fundamentos das formas da consciência social acima assinaladas [ciência, arte, moral, direito], mas também as capacidades, surgidas historicamente, que estão na base da consciência e do pensamento teóricos: a reflexão, a análise, o experimento mental.

Ao explicar a atividade de estudo, realizada por crianças em idade escolar a partir dos 6 anos de idade, o autor defende, em continuidade ao posicionamento de Vigotski, a importância da organização do ensino para que a atividade seja plena e da melhor qualidade, resultando no desenvolvimento humano omnilateral. Nesse ponto, o "papel do outro" ganha relevância. Por ser atividade humana, ela é um sistema de relações sociais com determinado grau de organização e desenvolvimento dessas próprias relações. Por isso, estão presentes nela, desde o princípio, as necessidades, os motivos, as vivências, os sentidos, as formas de atuar. Os sujeitos participantes dessa particular atividade formam e manifestam determinadas características de desenvolvimento psíquico que, ao mesmo tempo que servem, de base para ele, também o produz. Por isso,

não é algo passivel de ser realizado sozinho, é uma atividade conjunta, social. Pressupõe necessariamente a comunicação e a relação com o "outro", tanto pela produção cultural materializada em algum objeto material ou simbólico, quanto pela presença física desse “outro” (SERRÃO, 2006, p. 119).

Assim, tal atividade caracteriza-se como uma atividade interpsíquica, na qual os sujeitos nela envolvidos atuam conjuntamente para alcançar um objetivo comum, e aquele mais experiente - no caso, o professor-promove as condições 
necessárias às mediações para que o conhecimento e demais criações humanas sejam apropriados, ocorrendo o processo de internalização, que promove e dá continuidade ao desenvolvimento da atividade intrapsíquica. A atividade pedagógica é, então, relação social, interpessoal, dirigida a realizar ações pedagógicas, que, mediante a forma como produzem experiências no sujeito, o tornam capaz de produzir vivências, e o estudante atribui sentidos a tais experiências, entrando, assim, em atividade de estudo. Esse processo constitui-se, portanto, conforme a lei genética geral do desenvolvimento cultural, formulada por Vygotski (1995):

\begin{abstract}
[...] toda função em desenvolvimento cultural da criança aparece em cena duas vezes, em dois planos; primeiro no plano social e depois no psicológico, a princípio entre os homens como categoria interpsíquica e logo no interior da criança como categoria intrapsíquica. Isso se refere igualmente à atenção voluntária, à memória lógica, à formação de conceitos e ao desenvolvimento da vontade. Temos pleno direito a considerar a tese exposta como uma lei, a passagem, natural, do externo ao interno, modifica o próprio processo, transforma sua estrutura e função (VYGOTSKI, 1995, p. 150, grifos nossos).
\end{abstract}

Pelo exposto, Vigotski afirma que o desenvolvimento cultural da criança acontece, primeiro, externamente, ou seja, por meio das relações entre ela e o outro, ou entre as marcas simbólicas historicamente produzidas, denominadas, pelo autor, relações interpsíquicas. No processo de apropriação do legado cultural da humanidade, essa relação externa interpsíquica é internalizada, transformando-se num processo interno do sujeito, neste caso, chamado de intrapsíquica. Esse movimento é, a nosso ver, a constituição da natureza da atividade pedagógica.

A atividade pedagógica, portanto, como práxis, organiza-se pela unidade entre a atividade de aprendizagem e a atividade de ensino, particularmente quando relacionada à criança, pela unidade entre a atividade de comunicação emocional, de manuseio e utilização de objetos, sensório-motora, de comunicação não verbal e verbal, de brincar. De acordo com as peculiaridades de cada momento da existência do indivíduo como ser humano, a atividade pedagógica é caracterizada por elementos necessários para promover o desenvolvimento humano a partir da apropriação do conteúdo da cultura, em especial do conhecimento historicamente produzido e da formação do indivíduo como sujeito histórico, contribuindo de modo intrínseco para sua singularidade. Essas particulares atividades humanas, compreendidas cada uma em sua especificidade e em unidade, constituem-se na objetividade de forma única, indivisível. A atividade pedagógica não pode se realizar sem o objetivo final de promover a humanização do indivíduo e sua formação como 
ser singular. Esse objetivo contribui para a formação da personalidade, que é única e irrepetível, do sujeito individual, mas de natureza social. Realizadas por crianças, estudantes, adultos, têm como objetivo o próprio desenvolvimento humano e a necessidade social de constituírem-se como sujeitos, ao se relacionarem em sociedade.

Ao se considerar o exposto, é importante conhecer os elementos da organização desse tipo de atividade pedagógica para que se realize plenamente e promova o desenvolvimento humano omnilateral, como apresentamos a seguir.

\section{Elementos da ATIVIDAde PEdAGógicA PROMOTORA DO DESENVOLVIMENTO HUMANO OMNILATERAL}

Vigotski (2001, p. 333) defende que a pedagogia deve "orientar-se não no ontem, mas no amanhã do desenvolvimento da criança”. Partindo desse pressuposto, na organização da atividade pedagógica, faz-se necessário que o professor, na condição de responsável por essa organização, conheça as características do desenvolvimento da criança com idade de participar da educação pré-escolar e da educação escolar. Primeiro, consideramos importante que o professor compreenda que a educação da criança nunca parte do zero, como afirma Vigotski (2001, p. 111), "a aprendizagem da criança começa muito antes da aprendizagem escolar. [...]. Toda a aprendizagem da criança tem uma pré-história”. Por isso, vamos a partir daqui destacar alguns aspectos que consideramos importantes compreender para promover a atividade pedagógica de melhor qualidade.

Já é conhecido que desde seu nascimento a criança está em desenvolvimento. Ao entrar em contato com os elementos da cultura, por meio, principalmente nos primeiros dias e meses de vida, da atuação de adultos responsáveis por sua educação, a criança desenvolve suas funções psíquicas e começa o processo de tomada de consciência do contexto social do qual faz parte. A criança, inicialmente, se desenvolve ao participar de um processo de apropriação da função e uso dos objetos e dos meios que fazem parte desse contexto. Esse processo está diretamente relacionado às características da idade ou do seu período de vida.

Num estudo realizado em 1932, Vigotski apresenta a importância da periodização das idades para compreender 0 desenvolvimento infantil. Para ele, o conceito de idade difere daqueles tradicionalmente 
conhecidos $^{12}$, é definido pelo surgimento de novas formações psicológicas no desenvolvimento psíquico e da personalidade da criança. A periodização deve estar fundamentada

\begin{abstract}
[...] nas mudanças internas do próprio desenvolvimento; somente as viradas e os giros de seu curso podem nos proporcionar uma base sólida para determinar os principais períodos de formação da personalidade da criança que chamamos de idades (VYGOTSKI, 1932/1996, p. 254, grifos nossos).
\end{abstract}

Em cada idade uma função psíquica predominante dirige a aprendizagem e o desenvolvimento da criança ou do jovem, gerando novas formações psíquicas. Essas novas formações que servem como guia para o desenvolvimento, e que caracterizam "a reorganização de toda a personalidade da criança sobre uma nova base" (VYGOTSKI, 1996, p. 262), são chamadas de linhas centrais do desenvolvimento. As outras formações, que acompanham o desenvolvimento sem apresentarem uma relação com a formação guia, são denominadas por Vigotski de linhas acessórias do desenvolvimento.

Como o desenvolvimento é um processo dinâmico, essas linhas mudam de função de um período para outro, ou seja, aquelas funções que são consideradas linhas centrais em uma idade, na seguinte transformam-se em linhas acessórias. Nas palavras do autor,

\begin{abstract}
[...] se entende que os processos que são linhas principais de desenvolvimento em uma idade se convertem em linhas acessórias de desenvolvimento na idade seguinte e viceversa; isto é, as linhas acessórias do desenvolvimento de uma idade passam a ser principais em outra, já que se modifica seu significado e peso específico na estrutura geral do desenvolvimento, muda sua relação com a nova formação central. Na passagem de uma etapa de idade a outra se reconstrói toda sua estrutura. Cada idade possui sua própria estrutura específica, única e irrepetível (VYGOTSKI, 1996, p. 262, grifos nossos).
\end{abstract}

Mas o processo de desenvolvimento humano não se realiza considerando somente as relações internas do indivíduo. A qualidade da aprendizagem que provoca a formação do sujeito depende diretamente das condições que a criança tem de relacionar-se com o seu contexto social a partir das

12 A periodização do desenvolvimento infantil se baseava principalmente em elementos biológicos e evidentes externamente. De forma breve, Vygotski (1932/1996) cita as propostas de divisão do desenvolvimento dividindo-as em três grupos: o primeiro, baseado no princípio biogenético, periodiza o desenvolvimento de acordo com princípios biogenéticos, realizando um paralelo entre o desenvolvimento filogenético e ontogenético; o segundo propunha critérios convencionais, principalmente fisiológicos, para a periodização (como a dentição e a maturidade sexual); e o terceiro grupo se preocupa com o estudo das particularidades das mudanças internas do desenvolvimento. Este último é o que mais tem proximidade com os estudos realizados por Vigotski. 
situações sociais de desenvolvimento que vivencia. Cada etapa de vida da criança, cada momento do seu desenvolvimento, tem uma situação social do desenvolvimento com características específicas, pois ela é a "relação entre a criança com a realidade social" (DAVIDOV, 1988, p. 70), mediada por suas funções psíquicas e as interações com os mais experientes. 0 tipo e a qualidade da situação social do desenvolvimento dependem do processo de educação, aprendizagem e desenvolvimento que vai acontecendo. Ela não é uma estrutura dada a priori, e não acontece de maneira natural, mas é produzida na atividade pedagógica, organizada e planejada pelo professor. $\mathrm{E}$, quand o o professor considera a zona de desenvolvimento proximal da criança, promove constantemente novas situações sociais do desenvolvimento, ou seja, este é um processo dinâmico na atividade pedagógica.

A situação social do desenvolvimento é o ponto de partida para todas as mudanças que ocorrem na formação da consciência e da personalidade da criança; ela determina as neoformações que aparecem ao longo de cada idade no decorrer da vida do homem. Ela

determina plenamente e por inteiro as formas e a trajetória que permitem à criança adquirir novas propriedades da personalidade, já que a realidade social é a verdadeira fonte do desenvolvimento, a possibilidade que o social se transforme em individual (VYGOTSKI, 1996,

Considerando as linhas centrais e acessórias e a situação social do desenvolvimento, Vigotski apresenta a seguinte periodização das idades a partir desses elementos: primeiro ano (zero a 1 ano); primeiros anos da infância ${ }^{13}$ (1 a 3 anos); idade pré-escolar (3 a 7 anos); idade escolar (8 a 12 anos); crise dos 13 anos; puberdade (14 a 18 anos).

Além das características apresentadas acima, que fazem parte da dinâmica das idades, o autor apresenta outra característica importante para compreender as peculiaridades do desenvolvimento infantil: as crises. Elas representam o "acúmulo", o conjunto das apropriações realizadas pela criança em determinados períodos de tempo de existência. Vigotski apresenta uma distinção entre as idades. Há períodos, chamados estáveis, nos quais as mudanças ocorridas na personalidade da criança acontecem lentamente,

13 No texto em espanhol, traduzido do russo, lê-se "infância temprana"; a melhor tradução seria "primeira infância", porém preferimos utilizar a expressão "primeiros anos de vida da criança" para que não houvesse confusão entre a compreensão de infância e desenvolvimento infantil da Teoria Histórico-cultural e os pressupostos que fundamentam os estudos da Sociologia da Infância, que faz uso frequente da expressão "primeira infância”. 
de forma "microscópica”. São novas formações principalmente internas, quase impossíveis de serem percebidas no momento em que aparecem, porém, quando um grande número de mudanças ocorre, "se manifestam mais tarde como uma repentina formação qualitativamente nova de uma idade" (VYGOTSKI, 1996, p. 255). São mudanças bruscas, que demonstram alterações na personalidade da criança.

Por se produzirem, aparentemente, de forma repentina, as crises não têm idade ou tempo definido para acontecerem, e podem se manifestar por meio da dificuldade das crianças de se relacionar com aqueles com quem convivem. Para o autor, se compararmos o período de idade estável como o período de crise,

veremos que toda criança dessa idade é difícil de educar em comparação consigo mesma na idade estável contígua. E se passamos da apreciação absoluta à relativa na comparação dos avanços escolares da criança nos diversos períodos de idade, veremos que em toda criança, no período de crise, diminui o ritmo do rendimento que se caracterizava nos períodos estáveis (VYGOTSKI, 1996, p. 257, grifos do autor).

Por esse motivo, Vigotski destaca outra característica da crise das idades: "a índole negativa do desenvolvimento" (VYGOTSKI, 1996, p. 257). Ao ingressar na idade crítica, ou num período de crise, podem não aparecer novas formações ou novas atividades, mas o contrário. A criança pode perder "os interesses que antes ainda orientavam toda sua atividade, que antes ocupavam a maior parte de seu tempo e atenção, diz-se agora que se esvaziam as formas de suas relações externas, assim como sua vida interior" (VYGOTSKI, 1996, p. 257). Aqui se pode deduzir que aparentemente acontece um retrocesso, porém não há retrocesso na essência do desenvolvimento, mas uma mudança brusca de interesses.

Elkonin, fundamentado nos estudos de Vigotski e Leontiev, nos auxilia ainda mais na compreensão da periodização do desenvolvimento infantil. Segundo ele, as atividades não são realizadas de forma mecânica na vida do ser humano, mas assumem um caráter diretivo no desenvolvimento. Porém, somente algumas atividades assumem essa característica - são aquelas que estão diretamente relacionadas com o nível de desenvolvimento do sujeito. Nesse caso, em cada período, ou idade, há uma atividade principal que dirige a evolução psíquica e a formação da personalidade; as demais atividades atuam como auxiliares no desenvolvimento. Segundo o autor, 
a vida e a atividade, em geral, não se conformam de maneira mecânica a partir de alguns tipos de atividade. Alguns tipos de atividade são principais, fundamentais para um período, e têm enorme significado para o desenvolvimento posterior da personalidade, mas outros têm um significado menor. Por esta razão, não se deve falar da dependência do desenvolvimento psíquico com respeito à atividade em geral, mas da atividade principal. Em correspondência com isso se pode dizer que cada estágio do desenvolvimento psicológico se caracteriza por um tipo condutor (principal) determinado de sua atividade (ELKONIN, 2009, p. 195).

O autor define alguns períodos do desenvolvimento. São eles: no período pós-natal, a principal atividade dos bebês é a atividade de comunicação emocional imediata, que está direcionada ao adulto e tem como objetivo comunicar-se com ele. Essa atividade possui uma estrutura complexa e é realizada de maneira muito individual. Podemos dizer que as diferentes maneiras pelas quais se realizam são construídas por meio da interação da família (ou do adulto responsável pelo cuidado e educação da criança) com o bebê. É o produto do processo de como os adultos, ou o "outro" mais experiente, estabelecem relações interpessoais com o bebê e satisfazem suas necessidades biológicas. Essas criam outras necessidades, de afeto e da presença do adulto, e assim sucessivamente até o infinito e complexo desenvolvimento psíquico do sujeito.

Posterior a essa, desenvolvem-se as ações de orientação e a percepção sensório-motora. Essa formação é importante para o posterior domínio dos instrumentos. Nesse período de formação, o contato com os objetos e sua manipulação torna-se a atividade principal, deixando em segundo plano, mas presente, a comunicação não verbal e, posteriormente, o início da comunicação verbal. 0 adulto participa das ações das crianças como aquele que oferece o objeto e cria situações que auxiliam o seu manuseio, mas a atenção da criança está voltada para o objeto. Elkonin, ao buscar apreender esse momento do desenvolvimento humano, cria um conceito orientador para seu estudo, que denomina de fetichismo objetal. Para o autor, é como "se a criança não visse o adulto, como se estivesse encoberto pelo objeto e suas características" (ELKONIN, 2009, p. 202).

No terceiro período, na idade pré-escolar, aproximadamente de 3 a 7 anos, destaca-se a atividade de brincadeira de papéis sociais como a forma mais desenvolvida da brincadeira. Essa forma de atividade tem sua importância porque, além das inúmeras contribuições para a aquisição da linguagem e da manipulação de instrumentos, proporciona à criança a construção do sentido das relações sociais, por isso, "a brincadeira de papéis sociais participa como atividade, na qual realiza a orientação da criança para os sentidos mais 
gerais, fundamentais da atividade humana" (ELKONIN, 2009, p. 204). A partir das brincadeiras de papéis sociais, a criança realiza ações que têm valor social e geralmente são realizadas somente pelos adultos. O uso dos objetos pelas crianças é modificado, agora aparece com o significado social que lhe é atribuído, e contribui, mesmo que de forma inconsciente pela criança, para a apropriação das regras sociais.

Portanto, a criança, brincando, cria as bases para a atividade principal, a atividade de aprendizagem escolar, assim denominada por Elkonin (2009). Nessa etapa, surgem as formações intelectuais e cognitivas, e seu significado principal é que "medeia todo o sistema de relações da criança com os adultos que a rodeiam, até a comunicação pessoal em família [ou com quem a educa]" (ELKONIN, 2009, p. 204). A criança passa, então, a realizar atividades consideradas importantes socialmente, e ao entrar na escola, a relação com a família e amigos passa a ser mediada, também, pelos compromissos e exigências da escola. Ela passa a ter agora um compromisso social com a realização de ações correspondentes, as “tarefas”, segundo a denominação de Elkonin. Ao serem cumpridas, suas relações se ampliam, outros personagens passam a fazer parte do seu cotidiano e, com isso, novas experiências sociais e as produções de novas vivências, daí decorrentes, participam desse momento de vida da criança.

Na adolescência, a atividade principal é de comunicação entre os adolescentes. Segundo Elkonin, nesse período destacam-se as relações de amizades, "o outro adolescente como pessoa, com traços pessoais determinados" (ELKONIN, 2009, p. 205). Essas relações se baseiam nas relações dos adultos, com um conteúdo específico dos adolescentes, e produzem o sentido pessoal da vida. Nesse momento forma-se a base para a etapa seguinte, que é a atividade de estudo profissional.

Observamos que, nos estudos realizados por Vigotski e complementados por Elkonin, aqui destacados, o processo de desenvolvimento não ocorre de forma linear na vida da criança, mas é marcado por períodos estáveis e instáveis que promovem o avanço e, em alguns momentos, o aparente retrocesso no desenvolvimento. Outro aspecto que destacamos dos estudos é sua relação interdependente com a atividade humana. A atividade que dirige o desenvolvimento e promove o aparecimento de novas formações numa etapa será coadjuvante na etapa seguinte, servindo como base para outra atividade principal que promove o surgimento de outras formações e características no sujeito. Isso demonstra o aspecto dialético e de movimento constante do 
processo de humanização que se reflete no caráter dinâmico das relações sociais. Novos sentidos das relações pessoais e sociais aparecem e estão sempre em mudança. As vivências se ampliam, novos sujeitos aparecem e diferentes mediações são realizadas. Com isso, o sentido dessas novas experiências resulta na formação da personalidade dessas crianças como síntese de múltiplas determinações.

Para a organização da atividade pedagógica, principalmente na educação da criança, a importância da periodização está na compreensão dos nexos realizados por ela em cada momento de sua vida. Mesmo considerando que essas características não sejam fixas, ou seja, podem ocorrer em períodos cronológicos da existência diferentes daqueles definidos pelos autores, pois a situação social de desenvolvimento intervém diretamente na qualidade das novas formações, elas podem orientar, enquanto traços gerais, a atividade do professor.

Os estudos apresentados até aqui buscam destacar os elementos mediadores que consideramos importantes para a organização da atividade pedagógica. Ao destacarmos esses elementos, percebemos a importância da atividade na formação da consciência humana, que se caracteriza por um processo dinâmico de nexos externos e internos na psique do sujeito.

\section{AÇÕES POLÍTICAS NA ORGANIZAÇÃO DO SISTEMA EDUCACIONAL MEDIADORAS} NA ATIVIDADE PEDAGÓGICA

No início deste artigo, apresentamos que este trabalho resulta de uma pesquisa no Brasil e em Cuba. Nosso interesse no país foi compreender e identificar quais elementos permitem que o sistema educacional cubano seja considerado um dos melhores na América Latina e garanta o direito a todas as crianças de se desenvolverem de forma plena.

É importante esclarecer que o sistema educacional cubano tem seus fundamentos no pensamento educacional de José Martí, no século XIX, o qual, mesmo trazendo a presença de duas classes, no que se refere à educação, não deve haver diferença entre elas, pois a educação é o meio para a liberdade do povo. Apesar da referência a Deus, pensa na educação como meio para a construção de uma sociedade e para a produção da vida, afirmando que “[...] a educação precisa dar os meios de resolver os problemas que a vida venha a apresentar. Os grandes problemas humanos são: a conservação da existência e a conquista dos meios de fazê-la grata e pacífica (Obras escolhidas, vol. 22, p. 308)" (MARTí, 2007, p. 241, grifo nosso). 
O pensamento de José Martí demonstra que o interesse pela educação não se inicia com a Revolução de 1959, mas permite colocar em prática esses pressupostos valorizados pelos cubanos ao promover uma educação para o desenvolvimento integral do ser humano. Esses objetivos encontram, na década de 1960, fundamento na Teoria Histórico-cultural, que defende que o desenvolvimento do homem se dá a partir das relações com seu contexto social.

Em nosso período no país, evidenciamos alguns aspectos que contribuem para a atividade pedagógica e para o desenvolvimento humano omnilateral, que consideramos fazer parte de ações políticas para a manutenção da organização social proposta pelo governo revolucionário. Identificamos como ações políticas, especialmente, aquelas que formam o conjunto de estratégias que envolvem diferentes setores da estrutura do Estado, e que, de forma intersetorial, têm o objetivo final de atender às necessidades para a formação humana plena dos sujeitos.

Essas mesmas ações, por se efetivarem no conjunto das relações sociais, contribuem para a constituição dos sujeitos e ao mesmo tempo são constituídas por eles. Isso significa dizer que ao nascerem e participarem de relações sociais dessa qualidade, os cubanos as compreendem como necessárias para uma sociedade, e isso é transmitido não somente pelas vias institucionais, mas também apropriado nas relações sociais, por meio principalmente das atividades realizadas pela família, vizinhos, ou seja, no convívio social com os demais.

Nas ações realizadas pelos educadores cubanos na organização do sistema educacional, destacamos algumas que parecem evidenciar o movimento histórico e o compromisso com a formação humana omnilateral. Primeiro, percebemos a educação como um dos elementos principais das políticas do governo revolucionário. Como afirma Mészáros (2005), as mudanças na educação só acontecem acompanhadas de mudanças estruturais no modo de produção. Nas palavras do autor: “[...] uma reformulação significativa da educação é inconcebível sem a correspondente transformação do quadro social no qual as práticas educacionais da sociedade devem cumprir as suas vitais e historicamente importantes funções de mudança” (MÉSZÁROS, 2005, p. 25).

Desde 1959, o povo cubano, com o objetivo de superar o modo de produção capitalista, torna evidentes os pressupostos martianos em um conjunto de ações que preveem a melhoria da qualidade da educação de crianças, jovens e adultos. Para isso, cria organizações sociais voltadas para a educação de crianças que, mesmo inicialmente com caráter assistencial, possibilitava o 
estudo teórico e metodológico para garantir e efetivar a elevação progressiva dessa qualidade e, consequentemente, promover a formação de sujeitos compatíveis com a nova sociedade que se almejava.

Esse papel da educação na sociedade que se reestruturava nos leva a destacar um segundo elemento, a formação teórica e metodológica dos profissionais. O governo revolucionário, desde seu início, proporcionou a realização de pesquisas que tinham como objetivo compreender o desenvolvimento da criança como ser humano de direitos. Isso permitiu a aproximação dos pressupostos martianos com a Teoria Histórico-cultural. Essa aproximação se dá pela compreensão de que os estudos realizados por Vigotski e seus colaboradores eram os que melhor respondiam aos objetivos a que se propunham o governo revolucionário e os pesquisadores.

Desse modo, vemos aqui a efetivação da máxima em que o ser humano produz e é produto da história, pois nesse movimento revolucionário se vê efetivada a possibilidade de promover uma educação de formação humana integral. Cubanos e cubanas envolvidos nesse processo tornam-se participantes e sujeitos desse sistema educacional, exercitando princípios de uma sociedade que transcende a ênfase nas características individualistas do indivíduo, o que resulta, além de sua transformação, no comprometimento dos sujeitos com essa sociedade.

Esses dois elementos destacados nos levam à identificação de outra ação política voltada ao direito das crianças, o direito à educação pública, gratuita e integral da melhor qualidade para todas as crianças. Destacamos o caráter público e gratuito da educação cubana por se organizar, desde o princípio, como uma educação não somente em tempo integral, mas de formação integral das crianças. Esse caráter dado à educação abrange a busca de universalização da educação. Uma educação para além do conhecimento científico, mas do conhecimento teórico, ou seja, que de forma institucionalizada ou não proporciona às crianças situações de apropriação da cultura, dos valores morais, da ética, da estética, isto é, uma formação plena para o convívio em uma sociedade contrária à característica desumanizadora do capitalismo.

Esses elementos buscam garantir a universalização da educação, como afirma Mészáros (2005, p. 65), em um conjunto de mudanças da estrutura do modo de produção que se delineava em Cuba. Considerando, como o próprio autor afirma, que a universalização da educação e a universalização do trabalho como atividade humana autorrealizadora não podem acontecer separadas, o país ainda não atingiu essa segunda necessidade, por isso a universalização da educação ainda não se garantiu para todos os níveis de ensino, como, 
por exemplo, no nível superior. No entanto, Cuba demonstrou que é possível chegar o mais próximo possível com ações políticas de Estado e com a participação da população, pois a história se faz a cada ação intencional e com vontade política.

Ao expormos aqui nossas considerações acerca do que compreendemos como elementos mediadores presentes na educação cubana, no que se refere às ações políticas, aliado aos elementos trazidos anteriormente a partir dos estudos da Teoria Histórico-cultural, destacamos a importância do vínculo entre teoria e prática política. Esse vínculo promove ações voltadas para o desenvolvimento humano de melhor qualidade, garantindo às gerações mais jovens o acesso aos bens culturais, o desenvolvimento do pensamento teórico e o direito a usufruir os bens materiais resultados do processo histórico.

\section{CONSIDERAÇÕES FINAIS}

Ao apresentarmos os elementos mediadores para uma atividade pedagógica promotora do desenvolvimento, a partir dos fundamentos da Teoria Históricocultural e do sistema educacional cubano, buscamos destacar a importância em compreender esses elementos articulados, tanto os teóricos como os políticos. No movimento de estudo e análise desses elementos, percebemos que a teoria, desvinculada de vontade política para que se modifiquem as condições objetivas de produzir o humano no humano, resulta em tentativas difíceis de atingir seus objetivos.

Somente uma teoria que pense na criança como um ser social, que realiza suas atividades por meio das e nas relações sociais, articulada a uma política educacional voltada à garantia dos direitos das crianças permitirá uma atividade pedagógica promotora do desenvolvimento humano omnilateral. Para isso, são necessários formação teórica, compreensão do processo de desenvolvimento humano, posicionamento, organização e atuação políticas diante das condições históricas das relações sociais. Os elementos mediadores estão postos na formação política e social do ser humano. Se não alterarmos essas relações interpsíquicas no âmbito das relações sociais, não superaremos o estado de alienação que o modo de produção capitalista nos impõe. Para nós está claro que, em nosso país, ainda é necessário criar as bases para uma formação social emancipadora. Para isso, precisamos continuar investigando, produzindo arte, ciência, cultura e atuando politicamente na luta por uma educação de qualidade para criar as necessárias condições subjetivas e objetivas de formação humana. 


\section{Mediation in pedagogical activities: combining theory and practice}

Abstract: This article presents the findings of a study conducted in Brazil and in Cuba which aimed to understand the mediation elements involved in pedagogical activities in order to provide better quality education for children, i.e., education that can help them develop to their full potential. Initially, we present our view of human development, which stems from social relations, and approach the elements of these relations, particularly those associated with pedagogical activities, understood here as the combination of teaching and research. Finally, we stress that in order to understand the organization of pedagogical activities, which promote human development, it is necessary to understand child development elements, directing them to an education that allows learning situations that are suitable to children's development level and to the social situation of children's development.

Keywords: Cultural-Historical Theory. Human development. Pedagogical activity. 


\section{Mediación en la actividad pedagógica: la unidad entre teoría y práctica}

Resumen: Este artículo presenta los resultados de una encuesta realizada en Brasil y en Cuba que tiene como objetivo comprender los elementos mediadores de la actividad pedagógica para una educación de mejor calidad que promueva el desarrollo de los máximos potenciales de los niños. Inicialmente presentamos nuestra comprensión del desarrollo humano, resultado de las relaciones sociales, y analizamos los elementos de estas relaciones, particularmente los vinculados a la actividad pedagógica, entendida como la unidad entre la actividad de enseñanza y la actividad de estudio. Por último, destacamos que para organizar la actividad pedagógica, promotora del desarrollo humano, es necesario comprender los elementos que constituyen el desarrollo de los niños, orientados a una educación que proporcione situaciones de aprendizaje adecuadas al nivel de dicho desarrollo y a su situación social.

Palabras clave: Teoría histórico-cultural. Desarrollo humano. Actividad pedagógica. 


\section{REFERÊNCIAS}

ÁRIAS BEATÓN, Guillermo. La persona en lo histórico cultural. São Paulo: Linear B, 2005.

BERNARDES, Maria E. M. Mediações simbólicas na atividade pedagógica: contribuições da teoria histórico-cultural para o ensino e aprendizagem. Curitiba: CRV, 2012.

DAVIDOV, Vasili. La actividad de estudio en la edad escolar inicial. In: . La enseñanza escolar y el desarrollo psíquico. Moscou: Editorial Progresso, 1988. p. 158-190.

DAVYDOV, Vasili V.; ZINCHENKO, V. P. A contribuição de Vygotsky para o desenvolvimento da psicologia. In: DANIELS, Harry. Vygotsky em foco: pressupostos e desdobramentos. 2. ed. Campinas: Papirus, 1995.

ELKONIN, Daniil Borisovich. Hacia el problema de la periodización del desarrollo psíquico de la edad infantil. In: ROJAS, Luis Quintanar; SOLOVIEVA, Yulia. Las funciones psicológicas en el desarrollo del niño. México: Editorial Trillas, 2009.

ILIENKOV, Eduard V. Lógica dialectica: ensayos de historia y teoría. Moscou: Editorial Progreso, 1977.

LEONTIEV, Alexis. Artículo de introducción sobre la labor creadora de L. S. Vygotski. In: VIGOTSKI, L. S. Obras escogidas (Incluye el significado histórico de la crisis de la Psicología). Madri: Visor Distribuciones, 1991. tomo I.

O desenvolvimento do psiquismo. 2. ed. São Paulo: Centauro, 2004.

MANACORDA, M. A. Marx e a pedagogia moderna. São Paulo: Cortez, Autores Associados, 2007.

MARTí, José. Ideário pedagógico. 2. ed. Ciudad de La Habana: Pueblo y Educación, 1997.

MARX, Karl. Introdução à crítica da economia política. São Paulo: Abril Cultural, 1982. (Os Economistas). - O capital: crítica da economia política. Tradução Regis Barbosa e Flávio R. Kothe. 3. ed. São Paulo: Nova Cultural, 1988. (Os Economistas) [1867] 
MÉSZÁROS, István. A educação para além do capital. São Paulo: Boitempo, 2005.

MOURA, Manoel Oriosvaldo de (Org.). A atividade pedagógica na teoria histórico-cultural. São Paulo: Liber Livro, 2010.

PINO, Angel. 0 conceito de mediação semiótica em Vygotsky e seu papel na explicação do psiquismo humano. Cadernos Cedes, Campinas, n. 24, 1991.

SÁNCHEZ VÁZQUEZ, Adolfo. Filosofia da práxis. Rio de Janeiro: Paz e Terra, 2007.

SERRÃO, Maria I. B. Aprender a ensinar: a aprendizagem do ensino no curso de pedagogia sob o enfoque histórico-cultural. São Paulo: Cortez, 2006.

VIGOTSKI, L. S. Aprendizagem e desenvolvimento intelectual na idade escolar. In: ; LURIA, A. R.; LEONTIEV, A. N. Linguagem, desenvolvimento e aprendizagem. 9. ed. São Paulo: Ícone, 2001. p. 103-117.

VYGOTSKY, L. S. Internalização das funções psíquicas superiores. In: A formação social da mente: o desenvolvimento dos processos psicológicos superiores. 5. ed. São Paulo: Martins Fontes, 1994.

. Obras escogidas. Madri: Visor, 1996. tomo IV. Obras escogidas. Madri: Visor, 1995. tomo III.

\section{SOBRE A AUTORA}

Janaina Damasco Umbelino é doutora em Educação pela Universidade Federal de Santa Catarina (UFSC). Atualmente é professora do curso de Pedagogia e do Programa de Pós-graduação em Educação da Universidade Estadual do Oeste do Paraná (Unioeste), campus de Francisco Beltrão, Paraná, Brasil.

E-mail: janadumbelino@gmail.com.

Recebido em: julho de 2018

Aprovado em: agosto de 2018 